Canad. Math. Bull. Vol. 21 (4), 1978

\title{
HARDY INEQUALITIES WITH MIXED NORMS
}

\author{
BY \\ J. SCOTT BRADLEY ${ }^{(1)}$
}

Abstract. We give a necessary and sufficient condition on weight functions $u$ and $v$ such that for $1 \leq p \leq q \leq \infty$ there exists a constant $C$ for which

$$
\left(\int_{0}^{\infty}\left|u(x) \int_{0}^{x} f(t) d t\right|^{q} d x\right)^{1 / q} \leq C\left(\int_{0}^{\infty}|f(x) v(x)|^{p} d x\right)^{1 / p} .
$$

A corresponding dual result is also given. This extends a result of $B$. Muckenhoupt which appeared in Studia Math., 34 (1972).

1. Introduction. The classical Hardy inequality ([1], [2]) states that for $f(x) \geq 0$ and $p>1$

$$
\int_{0}^{\infty}\left[\frac{1}{x} \int_{0}^{x} f(t) d t\right]^{p} d x \leq\left(\frac{p}{p-1}\right)^{p} \int_{0}^{\infty} f(x)^{p} d x .
$$

Muckenhoupt, in [3], showed that the more general inequality

$$
\left(\int_{0}^{\infty}\left|u(x) \int_{0}^{x} f(t) d t\right|^{p} d x\right)^{1 / p} \leq C\left(\int_{0}^{\infty}|f(x) v(x)|^{p} d x\right)^{1 / p}
$$

holds if and only if

$$
\sup _{r>0}\left(\int_{r}^{\infty}|u(x)|^{p} d x\right)^{1 / p}\left(\int_{0}^{r}|v(x)|^{-p^{\prime}} d x\right)^{1 / p^{\prime}}=K<\infty
$$

and $K \leq C \leq K(p)^{1 / p}\left(p^{\prime}\right)^{1 / p^{\prime}}$. A similar result for the dual inequality

$$
\left(\int_{0}^{\infty}\left|u(x) \int_{x}^{\infty} f(t) d t\right|^{p} d x\right)^{1 / p} \leq C\left(\int_{0}^{\infty}|f(x) v(x)|^{p} d x\right)^{1 / p}
$$

was also obtained.

2. Generalized Hardy inequalities. Our results are the following:

THEOREM 1. Let $1 \leq p \leq q \leq \infty$. Suppose $u$ and $v$ are non-negative. Then

$$
-\left(\int_{0}^{\infty}\left[u(x) \int_{0}^{x} f(t) d t\right]^{q} d x\right)^{1 / q} \leq C\left(\int_{0}^{\infty}[f(x) v(x)]^{p} d x\right)^{1 / p}
$$

(1) Research supported in part by National Research Council.

Received by the editors November 1st, 1977 and, in revised form, February 24, 1978. 
holds for non-negative $f$ if and only if

$$
\sup _{r>0}\left(\int_{r}^{\infty} u(x)^{a} d x\right)^{1 / q}\left(\int_{0}^{r} v(x)^{-p^{\prime}} d x\right)^{1 / p^{\prime}}=K<\infty .
$$

Furthermore $K \leq C \leq K(p)^{1 / q}\left(p^{\prime}\right)^{1 / p^{\prime}}$ for $1<p<q<\infty$ and $K=C$ if $p=1$ or $q=\infty$.

The result on the constants is best possible since $K=C=1$ if $u$ is the characteristic function of $[1,2]$ and $v$ is 1 on $[0,1]$ and $\infty$ elsewhere while, if $p=q, C=K p^{1 / p}\left(p^{\prime}\right)^{1 / p^{\prime}}$ in the classical case.

Proof. To prove the theorem for $1<p \leq q<\infty$ we first suppose that (2.1) holds. A reduction in the intervals of integration yields

$$
\left(\int_{r}^{\infty} u(x)^{q} d x\right)^{1 / q}\left(\int_{0}^{r} f(x) d x\right) \leq C\left(\int_{0}^{r}[f(x) v(x)]^{p} d x\right)^{1 / p}
$$

and choosing $f(x)=v(x)-p^{\prime}$ gives (2.2) with $K \leq C$. To prove that (2.2) implies (2.1) we define $h(t)=\left(\int_{0}^{t} v(s)^{-\mathrm{p}^{\prime}} d s\right)^{1 / \mathrm{pp}^{\prime}}$. Then by Hölder's inequality and Minkowski's integral inequality [4] we see that

$$
\begin{aligned}
I & \equiv \int_{0}^{\infty}\left[u(x) \int_{0}^{x} f(t) d t\right]^{q} d x \\
& \leq \int_{0}^{\infty} u(x)^{q}\left(\int_{0}^{\infty}\left[f(t) v(t) h(t) \chi_{\{0 \leq t \leq x\}}(x, t)\right]^{p} d t\right)^{q / p} \\
\qquad & \times\left(\int_{0}^{x}[v(s) h(s)]^{-p^{\prime}} d s\right)^{q / p^{\prime}} d x \\
\leq & \left\{\int_{0}^{\infty}[f(t) v(t) h(t)]^{p}\left(\int_{t}^{\infty} u(x)^{q}\left(\int_{0}^{x}[v(s) h(s)]^{-p^{\prime}} d s\right)^{q / p^{\prime}} d x\right)^{p / q} d t\right\}^{q / p} .
\end{aligned}
$$

Performing the innermost integration yields

$$
\left(\int_{0}^{x}[v(s) h(s)]^{-p^{\prime}} d s\right)^{q / p^{\prime}}=\left(p^{\prime}\right)^{q / p^{\prime}}\left[\left(\int_{0}^{x} v(u)^{-p^{\prime}} d u\right)^{1 / p^{\prime}}\right]^{q / p^{\prime}}
$$

which by (2.2) is bounded by

$$
K^{q / p^{\prime}}\left(p^{\prime}\right)^{q / p^{\prime}}\left(\int_{x}^{\infty} u(s)^{q} d s\right)^{-1 / q}
$$

Hence

$$
I \leq\left(K p^{\prime}\right)^{q / p^{\prime}}\left\{\int_{0}^{\infty}[f(t) v(t) h(t)]^{p}\left(\int_{t}^{\infty} u(x)^{q}\left(\int_{x}^{\infty} u(s)^{q} d s\right)^{-1 / p^{\prime}} d x\right)^{p / q} d t\right\}^{q / p}
$$


and again evaluating the inner integral and applying (2.2) we obtain

$$
\begin{aligned}
\left(\int_{t}^{\infty} u(x)^{q}\left(\int_{x}^{\infty} u(s)^{q} d s\right)^{-1 / p^{\prime}} d x\right)^{p / q}=p^{p / q} & \left(\int_{t}^{\infty} u(s)^{q} d s\right)^{1 / q} \\
& \leq K p^{p / q}\left(\int_{0}^{t} v(s)^{-p^{\prime}} d s\right)^{-1 / p^{\prime}}=K p^{p / q} h(t)^{-p} .
\end{aligned}
$$

Consequently

$$
I \leq K^{q} p\left(p^{\prime}\right)^{q / p^{\prime}}\left\{\int_{0}^{\infty}[f(t) v(t)]^{p} d t\right\}^{q / p},
$$

which proves $(2.1)$ with $C \leq K(p)^{1 / a}\left(p^{\prime}\right)^{1 / p^{\prime}}$.

If $p=1$ and/or $q=\infty$ we show that (2.1) implies (2.2) by an argument which is essentially the same as the corresponding one used in [3] for the cases $p=1$ and $\infty$, and is hence omitted. To prove the reverse implication, if $p=1$ and $q<\infty$ we apply Minkowski's inequality to the leit side of (2.1) while, if $1 \leq p \leq q=\infty$ we use Hölder's inequality. The result follows immediately.

The following dual result is obtained analogously.

THEOREM 2. Suppose that $1 \leq p \leq q \leq \infty$ and that $u$ and $v$ are non-negative. Then

$$
\left(\int_{0}^{\infty}\left(u(x) \int_{x}^{\infty} f(t) d t\right)^{q} d x\right)^{1 / q} \leq C\left(\int_{0}^{\infty}[f(x) v(x)]^{p} d x\right)^{1 / p}
$$

if and only if

$$
\sup _{r>0}\left(\int_{0}^{r} u(x)^{q} d x\right)^{1 / q}\left(\int_{r}^{\infty} u(x)^{-p^{\prime}} d x\right)^{1 / p^{\prime}}=K<\infty .
$$

In addition $K \leq C \leq K(p)^{1 / q}\left(p^{\prime}\right)^{1 / p^{\prime}}$.

We single out the following specific case:

Corollary 1. Let $1<p \leq q<\infty$. Then if $a q>1, b p<1$ and $f$ is non-negative

$$
\left(\int_{0}^{\infty}\left[x^{-a} \int_{0}^{x} f(t) d t\right]^{a} d x\right)^{1 / q} \leq C\left(\int_{0}^{\infty}\left[x^{-a+1 / q+1 / p^{\prime}} f(x)\right]^{p} d x\right)^{1 / p}
$$

and

$$
\left(\int_{0}^{\infty}\left[x^{-b} \int_{x}^{\infty} f(t) d t\right]^{a} d x\right)^{1 / q} \leq C\left(\int_{0}^{\infty}\left[x^{-b+1 / q+1 / p^{\prime}} f(x)\right]^{p} d x\right)^{1 / p}
$$

\section{REFERENCES}

1. G. H. Hardy, Note on a theorem of Hilbert, Math. Z. 6 (1920), 314-317.

2. G. H. Hardy, Notes on some points in the integral calculus LX, Messenger of Mathematics, 54 (1925), 150-156. 
3. B. Muckenhoupt, Hardy's inequality with weights, Studia Math., 34 (1972), 31-38.

4. A. Zygmund, Trigometric Series, Volume I, Second Edition, Cambridge University Press, 1959.

\section{MCMASTER UNIVERSITY \\ Hamilton, Ontario \\ CANADA}

